\title{
Periodontal findings and platelet parameters
}

\author{
Beuy Joob • Viroj Wiwanitkit
}

Received: 17 December 2011 / Accepted: 24 February 2012 / Published online: 10 March 2012

(C) Springer-Verlag 2012

Sir, the recent report on periodontal findings and platelet parameters is very interesting [1]. López et al. concluded that "eosinophil counts and mean platelet volumes may reflect periodontal inflammation" [1]. There are some problems to be discussed. First, there are many confounding factors that can cause the periodontal disorders [2]. Of interest, those factors (such as personnel illness, smoking, drug usage, underlying genetic disorders, etc.) are not well controlled in this work. Second, not only the few subjects with no matching case-control design of the study but also the quality control of the use of blood cell analyzer might affect the result. The problem of using Abbott Cell Dyn 3500 analyser for platelet parameters analysis is mentioned in the previous literature [3].

\section{References}

1. López R, Loos BG, Baelum V (2012) Hematological features in adolescents with periodontitis. Clin Oral Investig (in press)

2. Kornman KS (2008) Mapping the pathogenesis of periodontitis: a new look. J Periodontol 79(8 Suppl):1560-1568

3. Müller TH, Döscher A, Schunter F, Scott CS (1997) Manual and automated methods for the determination of leukocyte counts at extreme low levels: comparative evaluation of the Nageotte chamber and the Abbott Cell Dyn 3500 analyser. Transfus Sci 18(4):505-515

B. Joob $(\bowtie)$

Sanitation 1, Medical Academic Center,

Bangkok, Thailand

e-mail: beuyjoob@hotmail.com

V. Wiwanitkit

Wiwanitkit House,

Bangkhae,

Bangkok, Thailand 